\title{
Peroral pyloromyotomy for the treatment of infantile hypertrophic pyloric stenosis
}

Infantile hypertrophic pyloric stenosis (IHPS) is the most common condition requiring surgical treatment in infants [1]. Traditionally, the standard treatments are laparoscopic or open pyloromyotomy [2]. Here, we report on the use of peroral pyloromyotomy (POP), also called gastric peroral endoscopic myotomy (G-POEM), which has shown promising results in the treatment of adult gastroparesis [3], for a novel application, the treatment of IHPS. A 35-day-old infant was admitted with a 1 -week history of progressively forceful vomiting after feeding. An ultrasound scan showed a thickened pyloric muscle and extended pyloric channel length and an upper gastrointestinal series showed narrowing of the pylorus, which was filled with a thin strip of contrast agent
( $\triangleright$ Fig.1a). The patient was therefore diagnosed as having IHPS. POP was proposed after a full multidisciplinary discussion.

The procedure included four steps ( Video 1): (i) a transversal mucosal incision was performed at the proximal antrum ( Fig.1b); (ii) a submucosal longitudinal tunnel was created across the pyloric ring ( $\mathbf{F i g . 1} \mathbf{c}$ ); (iii) full-thickness pyloromyotomy was performed, with a little extension at the antrum ( $\triangleright$ Fig.1 d), after which an ultrathin gastroscope was used to inspect the mucosa and pyloric outlet; (iv) after careful hemostasis had been performed, the mucosal entry was closed by clips ( $\mathbf{F i g .} \mathbf{1}$ e). The postoperative upper gastrointestinal series showed a normal stream of the contrast without evidence of any leakage (ฉ Fig.1f). The patient recovered well without any perioperative complications. During 2 months of follow-up, the patient took oral feeds well without vomiting and with an increase of $3 \mathrm{~kg}$ in body weight. Laparoscopic or open pyloromyotomy is the traditional standard treatment for IHPS [2]. However, because of severe dehydration, electrolyte disturbance, and malnutrition, these patients have a lower tolerance of surgery and recover more slowly than usual. In this video, we report the first application of POP in IHPS, which may indicate that POP is a minimally invasive, safe, and effective alternative for treating infants with IHPS.

Endoscopy_UCTN_Code_TTT_1AO_2AN
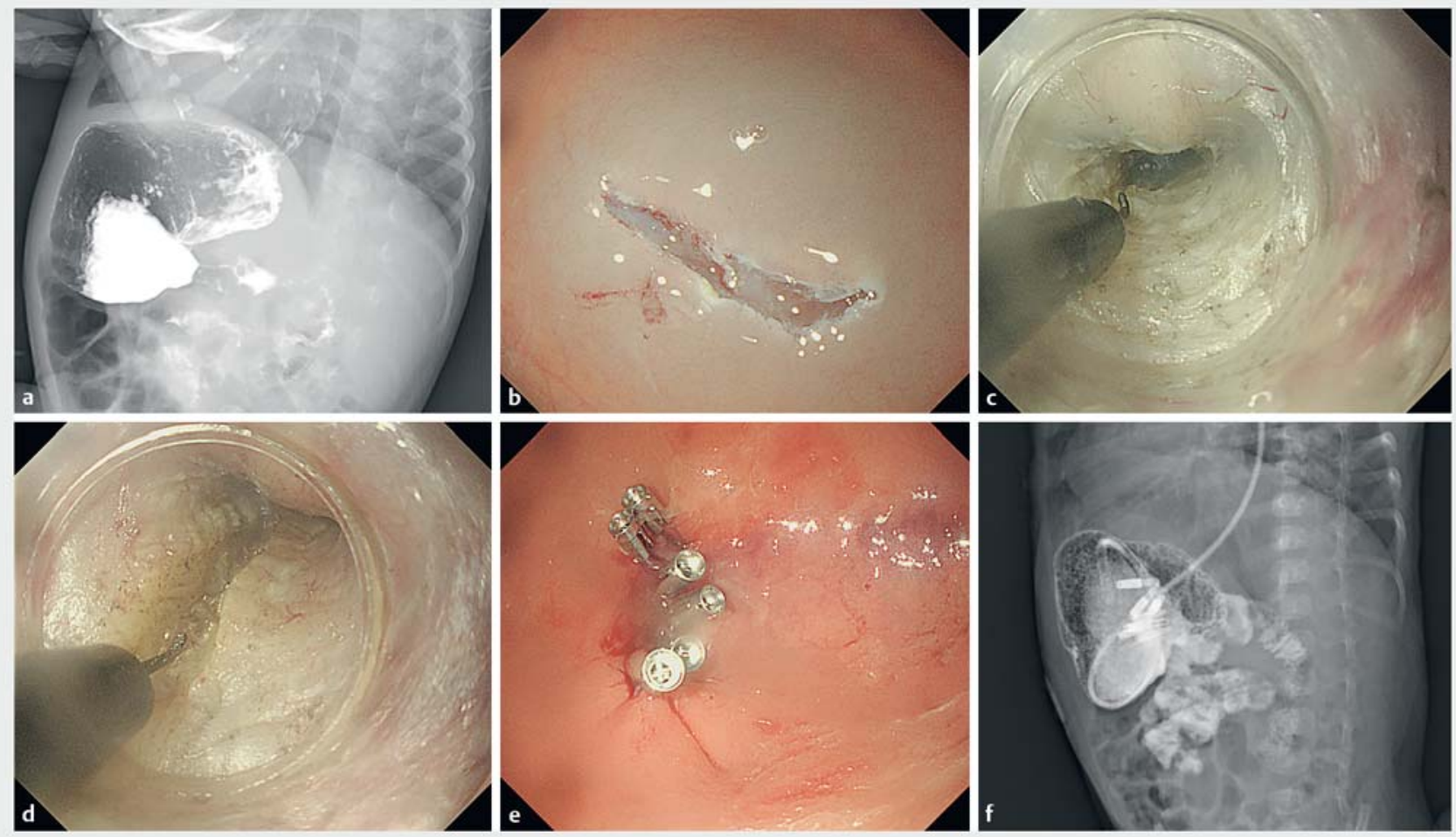

- Fig. 1 Peroral pyloromyotomy (POP) for the treatment of infantile hypertrophic pyloric stenosis in a 35-day-old infant. a The upper gastrointestinal series showed narrowing of the pylorus, which was filled with a thin strip of contrast agent. $\mathbf{b}-\mathbf{e}$ Endoscopic images showing: $\mathbf{b}$ mucosal incision at the entry site; c creation of a submucosal tunnel; $\mathbf{d}$ full-thickness pyloromyotomy; e complete closure of the mucosal entry site with clips. $\mathbf{f}$ Repeat upper gastrointestinal series 4 days after the POP showed the contrast now passed easily. 


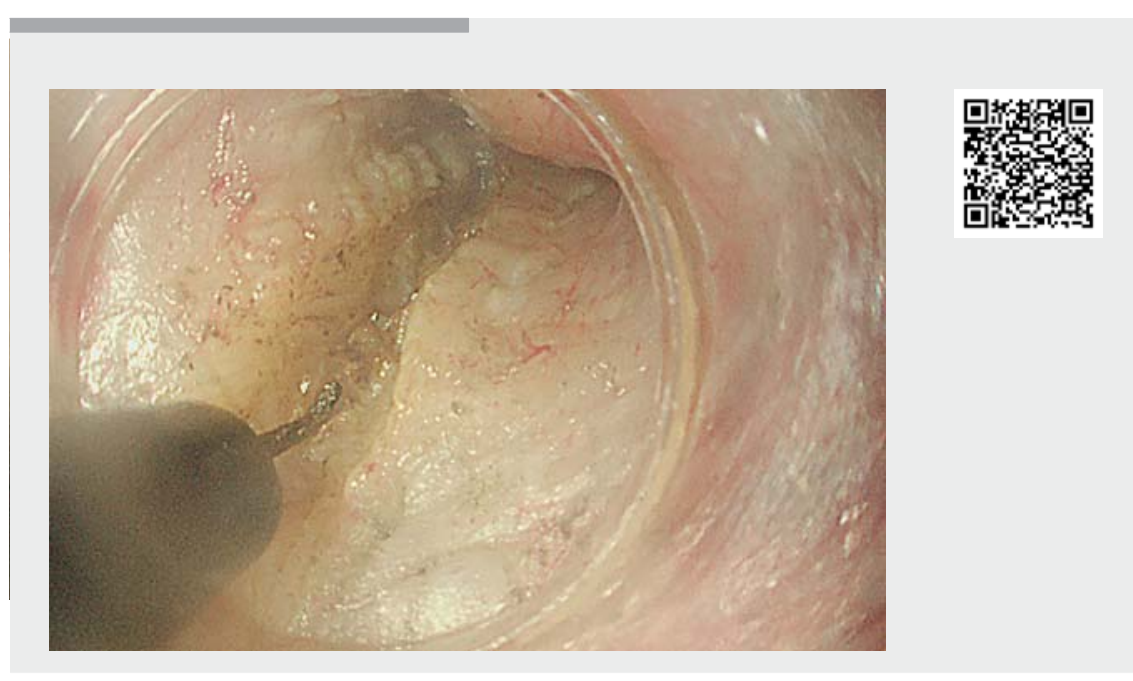

$\checkmark$ Video 1 Per-oral pyloromyotomy is performed to treat infantile hypertrophic pyloric stenosis with the following steps: a traversal mucosal incision was performed at the proximal antrum; a longitudinal submucosal tunnel was created across the pyloric ring between the mucosal and muscular layers (because of the narrow space and tender mucosa, the tunnel was performed along the muscular layer with more submucosal injections to avoid mucosal injury); full-thickness pyloromyotomy was performed, with a little extension to the antrum (because of the protection of intact mucosa, perforation is not a worry and any intraoperative bleeding was coagulated by hot biopsy forceps); the mucosal entry was closed by clips (the enlarged pyloric outlet can be seen through which the gastroscope could pass easily).

[1] Peters B, Oomen MW, Bakx R et al. Advances in infantile hypertrophic pyloric stenosis. Expert Rev Gastroenterol Hepatol 2014; 8: 533-541

[2] Sathya C, Wayne C, Gotsch A et al. Laparoscopic versus open pyloromyotomy in infants: a systematic review and meta-analysis. Pediatr Surg Int 2017; 33: 325-333

[3] Rodriguez J, Strong AT, Haskins IN et al. Per-oral Pyloromyotomy (POP) for medically refractory gastroparesis: short term results from the first 100 patients at a high volume center. Ann Surg 2018; 268: 421-430

\section{Bibliography}

DOI https://doi.org/10.1055/a-1022-4274

Published online: 25.10 .2019

Endoscopy 2020; 52: E122-E123

(c) Georg Thieme Verlag KG

Stuttgart · New York

ISSN 0013-726X

\section{ENDOSCOPY E-VIDEOS \\ https://eref.thieme.de/e-videos}

\section{Acknowledgment}

This study was supported by grants from the National Natural Science Foundation of China (81873552, 81570595, and 81670483), Shanghai Rising-Star Program (19QA1401900), Major Project of Shanghai Municipal Science and Technology Committee (18ZR1406700, 16411950400, 16DZ2280900), Outstanding Young Doctor Training Project of Shanghai Municipal Commission of Health and Family Planning (2017YQ026), and Chen Guang Program of Shanghai Municipal Education Commission (15CG04).

\section{Competing interests}

None

The authors

Zu-Qiang Liu ${ }^{1,{ }^{*}}$, Quan-Lin Li ${ }^{1,{ }^{*}}$, Jiang-Bin Liu², Hai-Feng Liu ${ }^{3}$, Hong $\mathrm{Ye}^{4}$, Ying Fang ${ }^{5}$, PingHong Zhou ${ }^{1}$
1 Endoscopy Center and Endoscopy Research Institute, Zhongshan Hospital, Fudan University, Shanghai, China

2 Department of Pediatric Surgery, Shanghai Children's Hospital, Shanghai jiao Tong University, Shanghai, China

3 Department of Gastroenterology, Hepatology and Nutrition, Shanghai Children's Hospital, Shanghai jiao Tong University, Shanghai, China

4 Department of Gastroenterology, Fujian Healthcare Hospital for Women and Children, Fuzhou, China

5 Department of Gastroenterology, The Children's Hospital of Xi'an City, Xi'an, China

\section{Corresponding author}

\section{Ping-Hong Zhou, MD, PhD}

Endoscopy Center and Endoscopy Research Institute, Zhongshan Hospital, Fudan University, 180 FengLin Road, Shanghai, 200032, P. R. China

Fax: +86-21-64038472

zhou.pinghong@zs-hospital.sh.cn
This section has its own submission website at https://mc.manuscriptcentral.com/e-videos

* Equal first authors 